\title{
The Effect of Artichoke Ethanolic Extract on Antibiotic-Resistant Clinical Strains of Staphylococcus aureus Isolated from Women
}

\author{
Bahman Fazeli-Nasab (iD ${ }^{1,},{ }^{*}$, Moharam Valizadeh ${ }^{2}$ and Maryam Beigomi ${ }^{3}$ \\ ${ }^{1}$ Research Department of Agronomy and Plant Breeding, Agricultural Research Institute, University of Zabol, Zabol, Iran \\ ${ }^{2}$ Research Center of Medicinal Plants, University of Sistan and Baluchestan, Zahedan, Iran \\ ${ }^{3}$ Department of Food Science and Technology, Zahedan University of Medical Sciences, Zahedan, Iran \\ "Corresponding author: Research Department of Agronomy and Plant Breeding, Agricultural Research Institute, University of Zabol, Zabol, Iran. Email: bfazeli@uoz.ac.ir
}

Received 2021 March 14; Revised 2021 May 15; Accepted 2021 May 16.

\begin{abstract}
Objectives: This study aimed to investigate the inhibitory and lethal effect of artichoke on pathogenic strains of Staphylococcus aureus and compare it with antibiotics in vitro.

Methods: Ten strains of S. aureus were isolated from the vagina of women in Amir Al-Momenin Hospital of Zabol, Iran. The resistance pattern was determined by the disk diffusion method. Finally, the effect of the extract on bacteria was determined by the 96-well microplate method.

Results: The results of the antibiotic resistance pattern showed that S. aureus samples had the highest resistance to oxacillin antibiotic and were sensitive to other antibiotics, and only one sample was sensitive to vancomycin antibiotic. The lowest inhibitory concentration of artichoke against S. aureus was $3.1 \mathrm{mg} / \mathrm{mL}$, but five strains were inhibited at a concentration of $6.25 \mathrm{mg} / \mathrm{mL}$.

Conclusions: Ethanolic extract had a significant inhibitory effect on the growth of S. aureus pathogens. Further clinical research is necessary for clinical use of these extracts.
\end{abstract}

Keywords: Cynara scolymus, Antibiotic Resistance, MIC, MBC, Pathogens

\section{Background}

Staphylococcus aureus is a gram-positive globular bacterium that occurs individually, in pairs or irregular clusters. Some of them live saprophytically on the skin and are responsible for more than $80 \%$ of purulent infections and cause infections in most parts of the body under the right conditions. These bacteria can cause pus, abscess formation, and various types of purulent infections (1).

Artichoke (Cynara scolymus) belongs to the genus Asteraceae, which grows mainly in the semi-desert regions of Armenia and Asia Minor. Its vegetative growth is long, starting in late June and lasting more than eight months. Its flowering is in late June, and its flowers reach full maturity in July (2). The stems and inflorescences of this plant are used in different parts of the world as a nutritious vegetable, tonic for the liver, and anti-inflammatory drug in reducing blood lipids and cholesterol (3). In traditional Turkish medicine, the dried seeds of this plant are used to treat the disease, and its fresh leaves are used as a diuretic (4). Its main medicinal properties are treating liver failure, increasing bile secretion, and lowering blood lipids (5-8). Artichoke hydroalcoholic extract can be effective in preventing type 1 diabetes (9).
Fungal and infectious diseases are among the most common diseases that impose a heavy financial burden on human societies. The incidence of opportunistic invasive fungal infections, often associated with high mortality, has increased over the past two decades. Patients who are severely immunocompromised due to underlying diseases such as leukemia or acquired immunodeficiency syndrome (AIDS), or and patients undergoing chemotherapy or organ transplants are severely immunocompromised, must beware of bacterial and fungal infections. Therefore, the main concern in treating fungal infections is the limitation of the number of effective antifungal drugs $(10,11)$. Many antifungal drugs have toxic effects, and since the majority of these drugs inhibit the growth of fungi and not fungicides, the disease recurs when this treatment is used. On the other hand, long-term treatment with a handful of these drugs leads to the development of drug resistance (12).

To reduce the economic loss and risks to microbial pathogens, the use of natural substances as antimicrobial compounds can be an effective way to control the presence of pathogenic bacteria. Meanwhile, extracts and essential oils of medicinal plants have antimicrobial prop- 
erties and act as sources of antimicrobial agents against pathogenic pathogens. Medicinal plant extracts show inhibitory effects against pathogenic bacteria; this inhibitory and lethal effect of various medicinal plants has been proven in several research studies $(13,14)$. Previous studies have shown the antioxidant and antibacterial activity of artichoke (15-17).

\section{Objectives}

This study aimed to investigate the inhibitory and lethal effect of artichoke on pathogenic strains of S. aureus and compare it with antibiotics in vitro.

\section{Methods}

\subsection{Preparation of Ethanolic Extract}

The artichoke plant (Figure 1) was collected and dried from Zabol, Iran. To prepare ethanolic, methanolic, and ethyl acetate extracts, $10 \mathrm{~g}$ of dry plant powder was placed in half-liter jars containing $100 \mathrm{ml}$ of $96 \%$ ethanol (for ethanolic extraction), methanol, and ethyl acetate. The contents of the Erlenmeyer flakes were mixed at room temperature for 24 hours with a shaker (Pars Azuma-Iran) at $130 \mathrm{rpm}$, then filtered through Whatman paper number 2. The solvent was separated from the extract by a rotary apparatus (Heidolph-Germany) using a vacuum pump (vacuum distillation). The obtained weighted extract was then dissolved in dimethyl sulfoxide (DMSO) solvent. The obtained extract was stored in the refrigerator at $4^{\circ} \mathrm{C}$ until use in antimicrobial tests.

\subsection{Bacterial Preparation and Storage}

In this study, different strains of S. aureus were isolated from the vagina of women in Amir Al-Momenin Hospital in Zabol city and cultured on specific culture media of mannitol salt agar and blood agar. The obtained pure strains were identified on an artificial culture medium using a hot staining test, catalase, and mannitol salt agar. Finally, S. aureus species were identified by coagulase test by tubular and slide methods, as well as studying agglutination formation. Bacterial strains were isolated by a range of biochemical, bacteriological, and growth tests (oxidase, catalase, and bacterial motility; glucose tests such as lactose fermentation, sucrose, and glucose), as well as regular tests such as gram staining and acid staining (18).

\subsection{Preparation of Bacterial Suspension}

After thawing, different strains of S. aureus were cultured linearly at $37^{\circ} \mathrm{C}$ in neutron broth medium. Pure colonies of bacterial samples were examined on Trypticase soy agar or tryptone soya agar (TSA) solid medium for 24 hours at $37^{\circ} \mathrm{C}$. The incubator was placed and, after 24 hours, removed from the pure colonies of each bacterium and made in sterile distilled water turbidity equivalent to half a McFarland. To ensure the concentration of bacteria, the UV visible spectrophotometer absorption was done at a reading wavelength of $600 \mathrm{~nm}$. Bacteria density in absorption of 0.08 - 0.1 have a concentration of $1.56 \mathrm{f} 10.6 \mathrm{CFU} / \mathrm{mL}$.

\subsection{Determining the Sensitivity of Bacterial Strains to Different} Extracts of Artichoke Plant

The sensitivity of bacterial strains to plant extracts was determined using the dilution method in wells. Six wells were made in solid culture medium, and $100 \mu \mathrm{L}$ of Müller Hinton nutrient medium (MHB) was added to each well. Then, $100 \mathrm{~mL}$ of diluted solution of plant extracts was added to the first well. After mixing, $100 \mu \mathrm{L}$ was removed from the first well and added to the second well, and so on until the last well. Next, $100 \mu \mathrm{L}$ of culture medium was removed from the last well, $10 \mu \mathrm{L}$ of microbial suspension containing 107 units/mL (equivalent to 0.5 McFarland) was added, and incubated at $37^{\circ} \mathrm{C}$ for 24 hours. The first well to inhibit bacterial growth after incubation was considered the minimum concentration of inhibitor. To ensure clear wells, $10 \mu \mathrm{L}$ was taken and transferred to Müller-Hinton agar medium. After 24 hours, the first dilution that was able to kill $99.9 \%$ of the bacteria had the minimum lethal concentration.

\section{Results}

The study of antibiotic resistance pattern showed that S. aureus samples had the highest resistance to oxacillin antibiotic and were sensitive to other antibiotics; only one sample was sensitive to vancomycin antibiotic (Table 1). However, the most significant sensitivity was observed in gentamicin antibiotic (Table 2).

The lowest minimum inhibitory concentration (MIC) of artichoke against $S$. aureus was $3.1 \mathrm{ppm}$, in which five strains were inhibited, while two bacterial strains did not grow at any concentration of artichoke extract. The highest minimum bactericidal concentration (MBC) of artichoke was 50 ppm, in which three strains were killed (Table 3).

\section{Discussion}

The results of studying the inhibitory and lethal effect of artichoke on pathogenic strains showed that the largest diameter of the growth inhibition zone of aqueous and ethanolic extracts of artichoke at a concentration of 800 $\mathrm{mg} / \mathrm{mL}$ belonged to $S$. aureus and yeast. Candida albicans and the lowest halo of Salmonella typhimurium were also reported. The MIC results of aqueous extract of artichoke 


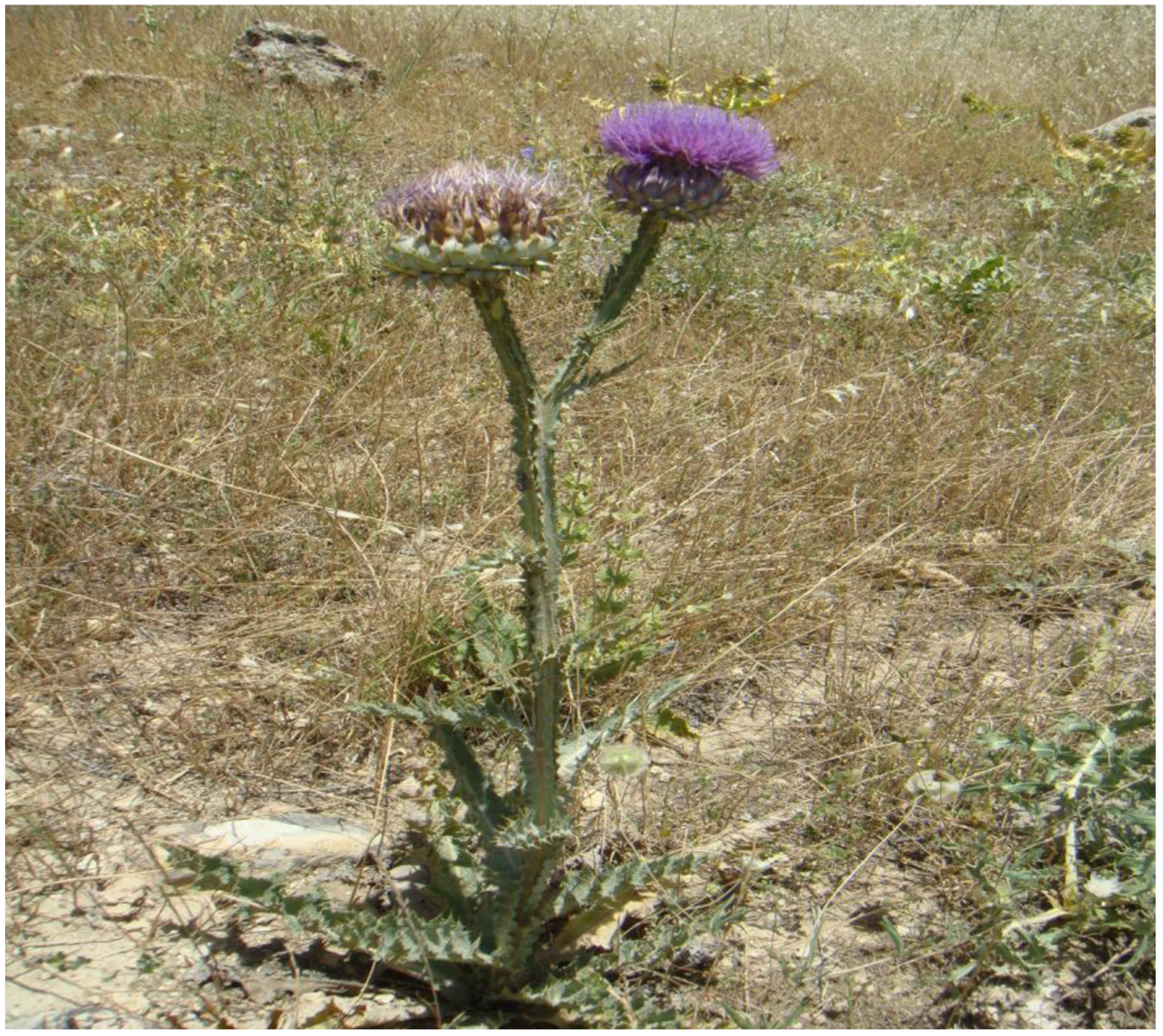

Figure 1. Appearance characteristics of artichoke

for S. typhimurium, Escherichia coli, S. aureus, Bacillus cereus, and C. albicans were 256, 32, 64, 64, and $32 \mathrm{mg} / \mathrm{mL}$, respectively, and for ethanolic extract were $128,32,16,16$, and 16 $\mathrm{mg} / \mathrm{mL}$, respectively (19). In the present study, for some strains, the minimum lethal and inhibitory concentration was $3.1 \mathrm{mg} / \mathrm{mL}$. This effect on the low concentration compared to the mentioned study (19) could be due to the type of extract. Alcohol has a more significant ability to extract antioxidants, and therefore alcoholic extract is more effective than aqueous extract (20).

For this type of bacteria, the standard type was not available in our laboratory. After ordering the standard samples, they were destroyed at the time of delivery, so we had to do the test without the standard samples. Although we re-ordered and later received healthy samples, we no longer used the standard samples in this test because the conditions of the test were different.

Inhibitory halo diameter of artichoke methanolic extract against B. cereus (1.003 0.03), Listeria innocua (0.00 02 $0.02)$, C. albicans (1.00 000.00$)$, and diameter of growth inhibitor zone of artichoke methanolic extract against $B$. cereus $(1 \pm 0.03 \mathrm{~cm})$, Listeria innocua $(1 \pm 0.02 \mathrm{~cm})$, C. albicans $(1 \pm 0.00 \mathrm{~cm})$, and $S$. aureus $(0.8 \pm 0.01 \mathrm{~cm})(21) S$. aureus $(0.01) \pm 0.80 \mathrm{~mm}(18,21)$.

Zhu et al. evaluated the antimicrobial activity of ethanolic extract and artichoke ethyl acetate against $15 \mathrm{mi}$ croorganisms, including seven species of Bacillus subtilis, S. aureus, Agrobacterium tumefaciens, Micrococcus luteus, E. 


\begin{tabular}{|c|c|c|c|c|c|c|c|c|}
\hline Strains & Oxacillin & & Amoxicillin Cloulanic Acid & Ampicillin & Gentamicin & Cefazolin & Azithromycin & Vancomycin \\
\hline 1 & Resistant & & Sensitive & Sensitive & Sensitive & Sensitive & Semi-sensitive & Resistant \\
\hline 2 & Resistant & & Sensitive & Sensitive & Sensitive & Sensitive & Sensitive & Sensitive \\
\hline 3 & Resistant & & Sensitive & Sensitive & Sensitive & Sensitive & Semi-sensitive & Sensitive \\
\hline 4 & Resistant & & Sensitive & Sensitive & Sensitive & Sensitive & Sensitive & Sensitive \\
\hline 5 & Resistant & & Semi-sensitive & Semi-sensitive & Sensitive & Semi-sensitive & Sensitive & Sensitive \\
\hline 6 & Resistant & & Sensitive & Sensitive & Sensitive & Sensitive & Sensitive & Sensitive \\
\hline 7 & Resistant & & Sensitive & Sensitive & Sensitive & Sensitive & Sensitive & Sensitive \\
\hline 8 & Resistant & & Sensitive & Semi-sensitive & Sensitive & Semi-sensitive & Sensitive & Semi-sensitive \\
\hline 9 & Resistant & & Sensitive & Sensitive & Sensitive & Sensitive & Sensitive & Sensitive \\
\hline 10 & Resistant & & Sensitive & Sensitive & Sensitive & Sensitive & Sensitive & Sensitive \\
\hline Strains & Oxacillin & & Amoxicillin Cloulanic Acid & Ampicillin & Gentamicin & Cefazolin & Azithromycin & Vancomycin \\
\hline $\mathbf{S}$ & 0 & & 90 & 80 & 100 & 80 & 80 & 80 \\
\hline I & 0 & & 10 & 20 & 0 & 20 & 20 & 10 \\
\hline $\mathbf{R}$ & 100 & & 0 & 0 & 0 & 0 & 0 & 10 \\
\hline Strain & MIC & MBC & \multicolumn{3}{|c|}{ Positive Control (Medium and Bacteria) } & \multicolumn{3}{|c|}{ Negative Control (Medium and Extract) } \\
\hline 1 & 25 & 50 & & Grew & & & Did not grow & \\
\hline 2 & 25 & 50 & & Grew & & & Did not grow & \\
\hline 3 & 25 & 50 & & Grew & & & Did not grow & \\
\hline 4 & 6.25 & 12.5 & & Grew & & & Did not grow & \\
\hline 5 & 6.25 & 12.5 & & Grew & & & Did not grow & \\
\hline 6 & 6.25 & 12.5 & & Grew & & & Did not grow & \\
\hline 7 & 6.25 & 12.5 & & Grew & & & Did not grow & \\
\hline 8 & 3.1 & 3.1 & & Grew & & & Did not grow & \\
\hline 9 & 6.25 & 12.5 & & Grew & & & Did not grow & \\
\hline 10 & 3.1 & 3.1 & & Grew & & & Did not grow & \\
\hline
\end{tabular}

coli, S. typhimurosa, four species of Polyporus albicans, Candida lusitaniae, Saccharomyces cerevisiae, and Saccharomyces carlsbergensis, and four molds, including Aspergillus niger, Penicillium oxalicum, Mucor mucedo, and Cladosporium cucumerinum (22).

The MIC of the extract was determined by agar and dilution broth methods in the range of 1.25 to $10 \mathrm{mg} / \mathrm{mL}$. The MIC was $2.5 \mathrm{mg} / \mathrm{mL}$ against fungi and $2.5 \mathrm{mg} / \mathrm{mL}$ against bacteria (22). Another study reported that artichoke hydroalcoholic extract inhibited E. coli and S. typhimurium (23). In the present study, the minimum lethal and inhibitory concentration was $3.1 \mathrm{mg} / \mathrm{mL}$, which is similar to the presented research.
Arbabian et al. studied the antimicrobial effects of aqueous-ethanolic-methanolic and Estonian artichoke extracts on some bacteria and fungi; the results showed that ethanolic and methanolic extracts of the organs had a growth inhibitory effect on the studied microorganisms. Also, ethanolic extracts prepared from different organs showed a more significant inhibitory effect than methanolic extracts. The inhibitory effect of ethanolic extracts was related to leaves. The highest effect of stem-flower organ extracts and edible part was seen on $S$. aureus and the most negligible effect on $B$. cereus. The highest antifungal effect was related to ethanolic extracts of the studied organs (24). The present study, which used an alcoholic extract, 
presented more effective results than previous studies that used aqueous extracts (19), and was similar to the results of another study (24).

\subsection{Conclusion}

The results of this study indicated the sound antimicrobial effects of artichoke extract against infections caused by S. aureus.

\section{Acknowledgments}

The authors wish to thank the Agricultural Biotechnology Research Institute, University of Zabol, Iran for assistance.

\section{Footnotes}

Authors' Contribution: All authors equally contributed to the study design, statistical analysis, and writing the manuscript.

Conflict of Interests: None of the authors have any conflict of interest to declare.

Funding/Support: The University of Zabol funded this study.

\section{References}

1. Bachert C, Humbert M, Hanania NA, Zhang N, Holgate S, Buhl $\mathrm{R}$, et al. Staphylococcus aureus and its IgE-inducing enterotoxins in asthma: Current knowledge. Eur Respir J. 2020;55(4). doi: 10.1183/13993003.01592-2019. [PubMed: 31980492].

2. Asgary S, Movahedian A, Badiee A, Naderi GH, Amini F, Hamidzadeh Z. [Effect of Gundelia tournefortii L. on some cardiovascular risk factors in animal model]. J Medicinal Plants. 2008;7(28):112-9. Persian.

3. Coruh N, Sag`dıçog lu Celep AG, Özgökçe F, İscan M. Antioxidant capacities of Gundelia tournefortii L. extracts and inhibition on glutathione-S-transferase activity. Food Chem. 2007;100(3):1249-53. doi: 10.1016/j.foodchem.2005.12.008.

4. Aburjai T, Darwish RM, Al-Khalil S, Mahafzah A, Al-Abbadi A. Screening of antibiotic resistant inhibitors from local plant materials against two different strains of Pseudomonas aeruginosa. J Ethnopharmacol. 2001;76(1):39-44. doi: 10.1016/s0378-8741(01)00206-9. [PubMed: 11378279].

5. Elmosallamy A, Abdel-Hamid N, Srour L, Hussein SAA. Identification of polyphenolic compounds and hepatoprotective activity of artichoke (Cynara Scolymus L.) edible part extracts in rats. Egypt J Chem. 2020;63(6):2273-85.

6. Frutos MJ, Ruiz-Cano D, Valero-Cases E, Zamora S, Pérez-Llamas F. Artichoke (Cynara scolymus L.). Nonvitamin and nonmineral nutritional supplements. Massachusetts, USA: Academic Press; 2019. p. 135-8. doi: 10.1016/b978-0-12-812491-8.00018-7.

7. Ehsani J, Mortazavian AM, Khomeiri M, Nejad AG. Effects of artichoke (Cynara scolymus L.) extract addition on microbiological and physico-chemical properties of probiotic yogurt. J Microbiol Biotechnol Food Sci. 2015;4(6):536-41. doi: 10.15414/jmbfs.2015.4.6.536-541.

8. Salekzamani S, Ebrahimi-Mameghani M, Rezazadeh K. The antioxidant activity of artichoke (Cynara scolymus): A systematic review and meta-analysis of animal studies. Phytother Res. 2019;33(1):55-71. doi: 10.1002/ptr.6213. [PubMed: 30345589].
9. Ahmadi Mahmoodabadi N, Madani H, Mahzooni P, Vahdati A. [Preventive effect of hydroalcoholic Cynara Scolymus extract on appearance of type 1 diabetes mellitus in male rats]. Iranian Journal of Diabetes and Metabolism. 2006;6(1):37-44. Persian.

10. Nenaah G. Antibacterial and antifungal activities of (beta)-carboline alkaloids of Peganum harmala (L) seeds and their combination effects. Fitoterapia. 2010;81(7):779-82. doi: 10.1016/j.fitote.2010.04.004. [PubMed: 20398742].

11. Fazeli-Nasab B. [Biological evaluation of coronaviruses and the study of molecular docking, linalool, and thymol as orfiab protein inhibitors and the role of SARS-CoV-2 virus in bioterrorism]. J Ilam Uni Med Sci. 2021;28(6):77-96. Persian. doi:10.29252/sjimu.28.6.77.

12. Emami S, Foroumadi A, Falahati M, Lotfali E, Rajabalian S, Ebrahimi SA, et al. 2-Hydroxyphenacyl azoles and related azolium derivatives as antifungal agents. Bioorg Med Chem Lett. 2008;18(1):141-6. doi: 10.1016/j.bmcl.2007.10.111. [PubMed: 18032039].

13. Anuar NS, Zahari SS, Taib IA, Rahman MT. Effect of green and ripe Carica papaya epicarp extracts on wound healing and during pregnancy. Food Chem Toxicol. 2008;46(7):2384-9. doi: 10.1016/j.fct.2008.03.025. [PubMed: 18468758].

14. Valizadeh M, Beigomi M, Fazeli-Nasab B. [Antibacterial and anti biofilm effects of ethanol and aceton leaf extract of Momordica charantia and Tecomella undulata against Acinetobacter baumannii]. International Journal of Advanced Biological and Biomedical Research. 2020;8(4):403-18.

15. Wang M, Simon JE, Aviles IF, He K, Zheng QY, Tadmor Y. Analysis of antioxidative phenolic compounds in artichoke (Cynara scolymus L.). J Agric Food Chem. 2003;51(3):601-8. doi: 10.1021/jf020792b. [PubMed: 12537429].

16. Zhu X, Zhang H, Lo R. Phenolic compounds from the leaf extract of artichoke (Cynara scolymus L.) and their antimicrobial activities. $J$ Agric Food Chem. 2004;52(24):7272-8. doi: 10.1021/jf0490192. [PubMed: 15563206].

17. Brat P, George S, Bellamy A, Du Chaffaut L, Scalbert A, Mennen L, et al. Daily polyphenol intake in France from fruit and vegetables. J Nutr. 2006;136(9):2368-73. doi: 10.1093/jn/136.9.2368. [PubMed: 16920856].

18. Shafiee P, Shoja A, Charkhabi AH. Biodegradation of polycyclic aromatic hydrocarbons by aerobic mixed bacterial culture isolated from hydrocarbon polluted soils. Iran J Chem Chem Eng. 2006;25(3):73-8.

19. Kolahi Marand S, Tabatabaei Yazdi F, Mortazavi SA, Beig Babaei A. Inhibitory and bactericidal effects of Artichoke (Cynara scolymus) on pathogenic strains and their comparison with antibiotics in vitro. Qom University of Medical Sciences Journal. 2016;10(2):32-42.

20. Fazeli-nasab B, Moshtaghi N, Forouzandeh M. Effect of solvent extraction on phenol, flavonoids and antioxidant activity of some Iranian native herbs. J Ilam Uni Med Sci. 2019;27(3):14-26. doi: 10.29252/sjimu.27.3.14.

21. Vamanu E, Vamanu A, Nita S, Colceriu S. Antioxidant and antimicrobial activities of ethanol extracts of Cynara Scolymus (Cynarae folium, Asteraceae Family). Trop J Pharm Res. 2011;10(6). doi: 10.4314/tjpr.v10i6.11.

22. Zhu X, Zhang H, Lo R, Lu Y. Antimicrobial activities of Cynara scolymus L. leaf, head, and stem extracts. J Food Sci. 2005;70(2):M149-52. doi: 10.1111/j.1365-2621.2005.tb07106.x.

23. Ionescu D, Predan G, Rizea GD, Mihele D, Dune A, Ivopol G, et al. Antimicrobial activity of some hydroalcoholic extracts of artichoke (Cynara scolymus), burdock (Arctium lappa) and dandelion (Taraxacum officinale). Bull Transilv Univ Bras II For Wood Ind Agric Food Eng. 2013;6(2):113.

24. Arbabian S, Akhondzade Darian M, Akhavan Sepahi A, Chalabian F. [The study of antimicrobial effects of ethanolic, methanolic, acetonic and aqueous extracts of Cynara scolymus on some of bacteria and fungi]. Journal of Microbiology Knowledge. 2009;1(4):21-8. Persian. 